\title{
Crónica de un desencanto: la transición a examen en la literatura policíaca de Manuel Vázquez Montalbán y Juan Madrid
}

\author{
DIEGO ERNESTO PARRA SÁNCHEZ
}

\section{Planteamiento inicial}

La narrativa policíaca experimenta en España una eclosión sin precedentes en la década de los años setenta a la sombra de las vertiginosas transformaciones políticas sociales y económicas que trae consigo el proceso de transición democrática. Con rúbricas como las de Vázquez Montalbán, Juan Madrid, Martínez Reverte, González Ledesma, Andreu Martín o Julián Ibáñez entre las más representativas, este discurso literario debe ser entendido como trampolín, por su ligazón a las problemáticas urbanas a pie de calle, su superdotada capacidad para la recreación realista y su carácter de literatura de masas, para el retrato crítico de un momento o período histórico determinado.

En el caso de España en una vertiente parricida, dado que esta nueva novela policíaca, heredera del hard boiled de los maestros norteamericanos, se dedica a cuartear la realidad de la España de este período en un discurso cargado de reflexiones críticas sobre los hitos fundamentales del mismo movimiento que propicia su nacimiento, desarrollo y auge en España. En este cuestionamiento de la Transición, o si se prefiere, esta evaluación continua de su desarrollo, de sus logros y, sobre todo, de sus fracasos, descuellan sobre todo las voces de Manuel Vázquez Montalbán, con su saga protagonizada por Carvalho y ambientada en Barcelona, y Juan Madrid, con su serie "Toni Romano" localizada en Madrid. A lo largo de estas páginas, tras presentar un breve repaso sobre la historia de esta literatura popular en España desde sus orígenes hasta la caída del régimen franquista, se ahondará en esta narrativa criminal entendida como una plataforma para la reflexión crítica sobre el período transicional en torno a cuatro ejes fundamentales: el político, el económico, el social y el relativo a los medios de comunicación. 


\section{Breve historia del género policíaco en España hasta 1975}

Hasta este momento, su práctica se había limitado a un número reducido de autores y obras poco trascendentes. Aunque el escritor granadino Pedro Antonio de Alarcón es considerado por muchos como el precursor de este género en España a raíz de la publicación en 1853 de su relato "El clavo"1 (una investigación judicial en torno al asesinato de una persona al aparecer un cadáver con un clavo en el cráneo), su primera cultivadora stricto sensu, ya no solo como autora sino también a través de estudios sobre el género, fue Emilia Pardo Bazán. En el año 1905 publica el cuento "Misterio", y en 1911 "La cana" y "La gota de sangre". Caracterizados por un primitivismo tanto a nivel de estilo como a nivel argumental, se trata de textos que siguen fielmente el modelo británico de detective aficionado que resuelve un crimen por medio de la observación detallista y la deducción. Su contribución inaugural terminaría con la publicación en 1913 de Belcebú, aunque posteriormente el profesor Benito Varela Jácome descubriría un manuscrito titulado Selva que podría suponer la continuación de "La gota de sangre": un escrito inédito compuesto por ciento sesenta y ocho cuartillas redactadas a mano y llenas de tachaduras y correcciones, lo que parecería "demostrar el escaso interés de la autora por concluir esta novela y la pérdida de entusiasmo en cuanto a la literatura policial en sus últimos años" (Bados 31).

Anteriormente, en 1909, Joaquín Belda y Manuel A. Bedoga habían publicado la novela ¿Quién disparó?: una parodia de Sherlock Holmes y el Dr. Watson que se hizo popular en la época entre unos lectores que empezaban a disfrutar con las traducciones de clásicos del género principalmente exponentes del relato de enigma- anglosajones. La aplicación de manera estricta de los convencionalismos del whodunnit, bien desde el pastiche, bien por medio de la parodia seguirá siendo común denominador durante las décadas siguientes hasta el año 1936.

Con el estallido de la guerra civil y la consiguiente llegada de la dictadura franquista, la publicación de esta literatura decae y, aunque se siguen editando traducciones extranjeras, la censura lleva a cabo una

\footnotetext{
1 A diferencia de lo que una parte de la crítica especializada sostiene, en este trabajo no vamos a considerar a Pedro Antonio de Alarcón y su relato breve "El clavo" (1853) como autor y obra inauguradoras del género en España por entender que guarda mayor relación con el género de crónica de crímenes reales o causas célebres.
} 
labor de depuración más que notable en consonancia con los valores sociales que se pretendían fomentar.

Es preciso destacar también que este valor cultural seguía considerándose entre el público español como un valor ajeno y extranjerizado. No solo el hecho de que la mayoría de las obras que se publicasen fueran traducciones de obras de otros países -o simples recreaciones emuladoras del relato de enigma-, sino también la recurrencia a investigadores foráneos y ubicaciones extranjeras era una constante en la época. Así, a la hora de caracterizar y localizar tanto personajes como ubicaciones, los escritores españoles se decantarán por dos países principalmente: Reino Unido -como Fernández Flores o August Jordana- y Estados Unidos -Pérez Capo o Marsá Becal-(Close 126).

Sin duda, uno de los autores que con más precisión ha explicado este fenómeno -valiéndose de su vasta experiencia tanto como editor como escritor para la editorial Bruguera- es Francisco González Ledesma:

La gente de la calle no hubiera admitido inspectores Gómez ni criminales Rodríguez, ni calles conocidas que no excitaran sus sueños y sus ansias de viajar. Todo lo bueno sucedía entonces fuera de España, y las únicas policías con garantía de origen eran Scotland Yard y el FBI, sobre todo este último.

[...] De modo que por esas razones tan importantes nadie escribía novelas policiacas ambientadas en las ciudades españolas y encima con sentido crítico, es decir lo que hoy llamaríamos ya "novela negra". Los argumentos se desarrollaban en Inglaterra, Estados Unidos y excepcionalmente en Francia. En lugares oficialmente tan corruptos era posible situar grandes "gangs", policías que cobraban bajo mano, gobernantes venales y hasta alguna señorita que enseñaba el portaligas, si bien esa prenda íntima nunca pudo mencionarse de una forma expresa (González 12).

Por el contrario, el escritor Mario Lacruz y su novela El inocente (1953) suponen una interesante excepción en el panorama de escritores españoles de policíaco durante la posguerra. La novela de Lacruz escapa conscientemente de la tradición importada de novela policíaca clásica e inicia al mismo tiempo un acercamiento del género hacia formas de mayor calado por medio de una imbricación novedosa de, por un lado, el aspecto lúdico del interrogante policíaco ágilmente narrado, y, por otro, la observación profunda de lo humano conjugada con una mayor experimentación técnica. De hecho, el propio Lacruz reconoce en este sentido la influencia del autor belga George Simenon, al incorporar, como sos- 
tiene la profesora Julia Luzán, la introspección psicológica a su producción enriqueciendo con ello en gran medida esta literatura: "De Simenon también [...] en la capacidad de, con muy pocos medios, crear un clima o un personaje y meterte enseguida en él" (Luzán 36).

En síntesis, según José Colmeiro, Lacruz combinaría "elementos de vanguardia narrativa, como la profundidad psicológica, el perspectivismo o la ruptura del orden lógico temporal, con ingredientes clásicos de la intriga policiaca, obteniendo un resultado novedoso" (Colmeiro 141).

Para terminar con este apartado, en las décadas de los años cincuenta y sesenta, aparecen los investigadores Manuel González, alias Plinio, de la policía municipal de Tomelloso, y su acólito Don Lotario, el veterinario del pueblo. Con novelas como El reinado de Witiza (1967) o Las hermana coloradas (1970), la práctica del género en España toma en las manos del autor Francisco García Pavón la forma de historias policíacas auténticamente enraizadas en nuestro país inaugurando una tendencia autóctona alejada de los moldes imperantes anglosajones. En ella, el enigma va cediendo terreno a favor del retrato costumbrista de La Mancha profunda, trasunto de la España rural bajo el régimen franquista, con una minuciosa descripción de lugares, costumbres y tipos humanos del momento. Aunque, por supuesto, se tratará todavía de una literatura policíaca en la que la realidad social estará expuesta -como escribe el crítico Javier Villán en su prólogo a la edición de Las hermanas coloradas de la colección "Biblioteca El Mundo"- "con la moderación sentimental propia de un moderado como era el autor manchego" (García 7). Para muestra, el siguiente extracto donde García Pavón se refiere a la falta de pluralidad política desde el humor y el costumbrismo en los siguientes términos:

[Plinio] compró el Lanza [periódico deportivo] [...] y volvió a su despacho sin ninguna perspectiva de amenidad para aquella mañana. Leyendo el Lanza que hablaba muy por menudo de los partidos de fútbol jugados el día anterior en todos los pueblos de la provincia, según costumbre de la prensa de este país, que por algo se dice que vivimos en un régimen de partido único (García 18-19).

\section{El Boom editorial de la narrativa policíaca en España a partir de 1975}

Son tres las razones que, históricamente, se han enumerado en relación a la falta de una tradición consolidada de literatura policíaca española: 
razones políticas, razones de naturaleza editorial y razones sociohistóricas. En lo que atañe a las primeras, hay que comentar las complicaciones que podían representar su cultivo y promoción en un régimen autoritario como el franquista, sobre todo en su vertiente negra o hard boiled, por su dimensión realista y su inclinación inherente al retrato crudo de la realidad social a pie de calle. Esto explica que, durante el franquismo, tanto escritural como editorialmente, existiera una predilección por el relato clásico de enigma o whodunnit debido a sus menores implicaciones críticas; las pocas muestras de novelas negras que llegaban, en cambio, no conseguían superar la censura oficialista. Así ocurriría con la publicación de Lady in the lake (1943) de Raymond Chandler que, publicada por la editorial Mateu ${ }^{2}$ en 1962 bajo el título La "dolce vita" en América, "fue objeto de censura siendo varios pasajes mutilados" (Vallés 80). Entre las razones de naturaleza editorial, sobresale la de la consideración negativa que acompañó al género en nuestro país desde sus primeras manifestaciones y que obligaba a los pocos autores que practicaban el género a utilizar ubicaciones extranjeras para localizar sus tramas o a esconder sus identidades bajo pseudónimos (Fernández 10).

Efectivamente, las convenciones sociales y críticas de carácter elitista, que han sido las dominantes durante mucho tiempo en España, tendían a integrar la novelística criminal en el campo de la "subliteratura" generalizándose una infravaloración de la misma que motivó, sin duda, la exigua práctica de este tipo de literatura en este país: "No ha habido en España escritores especializados en novela policiaca y dedicados a ella como su medio normal de expresión, [...] a causa de la deplorable consideración social [...] que ha tenido en nuestro país" (Vázquez de Parga 24). Sin embargo, ninguna de estas razones explica tan bien la ausencia de tradición literaria policíaca en España como ciertas motivaciones sociohistóricas, ya que este género "presupone unas condiciones particulares para su surgimiento tales como la existencia de un sistema democrático pluralista, una sociedad capitalista avanzada y una demografía urbana desarrollada" (Colmeiro 263).

2 Empresa editorial con sede en Barcelona fundada por Francisco F. Mateu en 1945 dedicada a la publicación de obras sensacionalistas, así como cómics o literatura infantil, tanto en castellano como en catalán. 
La novela policíaca surge en un contexto de legitimación de la ideología jurídica de la burguesía industrial, y es precisamente la falta de esta ideología la que explica, en última instancia, su inexistencia en España hasta la década de los setenta. Hay que esperar hasta el final de la dictadura franquista y el consiguiente advenimiento de la democracia para ver eclosionar esta literatura en un país donde se empiezan a dar los conflictos políticos, sociales y económicos propios de las ciudades modernas industrializadas bajo el amparo de una libertad de expresión y de edición que empieza a permitir la reflexión crítica -libre ya de las amputaciones ocasionadas por la censura dictatorial- sobre la realidad del momento y su problemática: principalmente las fisuras del movimiento transicional democrático provocadas por la subsistencia de agentes políticos continuistas entre las esferas gubernamentales. Sólo así se propicia la atmósfera que posibilita el desarrollo editorial del género en España y el surgimiento de un público lector cada vez más masivo. Como concluye la profesora Mari Paz Balibrea: "público e industria se retroalimentarán mutuamente a partir de la transición para generar un fenómeno cultural que surge durante la esta época pero que no habría sido posible en su extensión y alcance sin los desarrollos socioeconómicos e ideológicos del tardofranquismo" (Balibrea 113); en definitiva, un contexto en el que el capitalismo, tardío y circunscrito a zonas concretas, aparece en su forma plena provocando que en los grandes centros urbanos surjan fenómenos propios de la ciudad capitalista entre los que arraiga sólidamente esta literatura, como la soledad, la desigualdad o la violencia.

\section{Policíaco y Transición: crítica política}

Si hay algo que traslucen las propuestas literarias criminales de los autores de esta generación -y muy especialmente las de Montalbán y Madrid-es la pervivencia de personalidades franquistas en puestos de influencia política tras la muerte del generalísimo. Lejos de romper de raíz con el sistema dictatorial, se vislumbra un continuismo ideológico notable bajo la forma de un nuevo partido político: Alianza Popular, que tanto en Montalbán como en Madrid activa la ecuación "transición" = "camuflaje", pese a la derogación superficial de las estructuras del Movimiento Nacional. Como dice Juan Madrid en Un beso de amigo primera novela de la saga- por boca de su protagonista, el ex policía 
franquista y ex boxeador abjurado de la policía franquista: “ ¿Y pedir el reingreso en el cuerpo ahora que se ha muerto el General y han cambiado los tiempos? Pero ¿han cambiado realmente?" (Madrid 96). En esta misma línea se expresa el escritor Francisco Javier Satué en un interesante prólogo también a la edición de "Biblioteca el Mundo" de Tatuaje (1974) de Vázquez Montalbán: “¿Quién iba a decirnos que, tras la interminable postguerra y el drama de la lucha contra Franco y su régimen, "popular" iba a convertirse en divisa de los estandartes de sus secuaces, como Fraga y sus apóstoles" (Vázquez, 2001a: 7).

Otros dos fracasos de la transición en materia política que son aludidos a lo largo de estas sagas, son, por un lado, el hecho de que la transición no haya sabido -o no haya querido- mitigar el atávico conflicto entre las dos Españas en una dialéctica electoral bipartidista entre el Partido Popular, heredero a su vez de Alianza Popular, y Partido Socialista Obrero Español que, sin duda, era una vuelta a una especie de turnismo político, respaldado por una cobertura mediática también partidista y clientelar, con el fin de estabilizar España en materia de política interior. A este respecto, en Los mares del sur se reflexiona sobre esta realidad en un tono no exento de la ironía que caracteriza los textos del autor catalán:

¿Qué régimen político predominará en ese futuro paradisíaco [nótese la ironía en referencia a la España democrática] me preguntará usted. Y yo le responderé una socialdemocracia muy liberal cuando no un liberalismo muy socialdemócrata. En el caso de que no haya guerra y continuemos por la vida coexistencial (Vázquez, 2001b: 64).

Por otro lado, el otro gran "no logro" de la transición, y que se revela con el tono premonitorio de quien tan bien supo interpretar la sociedad en plena transformación que sus novelas policíacas reflejan, es la no resolución de los conflictos nacionalistas o de las que, en terminología transicional se dieron en llamar con la voz eufemística de "regiones históricas". Como sugiere Vázquez Montalbán en el siguiente fragmento de Pájaros de Bangkok, la España de la Constitución del 78 ha fallado en la creación de un mapa político-social integrador lo suficientemente atractivo como para, una vez concluida la efervescencia transicional y asentada una dinámica democrática más o menos estable, atenuar a favor de un 
proyecto común las identidades vasca, gallega y catalana gravemente inhibidas durante el franquismo:

-Lo extraño es que aquí en Barcelona no se ha notado alegría por la victoria socialista [en los comicios de 1982]

- [...] Es cierto, aquí no hubo la alegría que hubo en Madrid

-Toma, porque los socialistas catalanes saben que las elecciones se las ha ganado Felipe González y eso tiene un precio.

-A mí que no me toquen Catalunya. Alzaba el pintor con tozudez etílica.

-Porque por delante de todo soy catalán (Vázquez, 1990: 217).

A nivel legislativo, si bien la Carta Magna del 78 atestiguaba una importante apertura en este sentido con el reconocimiento de derechos tan importantes como los de edición, asociación política libre o libertad de expresión, además de la firma de una Amnistía total por delitos de disidencia política o la legalización de partidos como el Partido Comunista Español (ambos acontecimientos en 1977), desde el policíaco de estos autores sorprende el mantenimiento, aunque no en su totalidad, sí en una parte sustancial la Ley franquista de Vagos y Maleantes en materia de seguridad ciudadana. Configurada a partir de la Ley "Gandula" aprobada durante la II República en España en 1933, con el objetivo principal de controlar la mendicidad, es ampliada posteriormente por el régimen (1954) y utilizada como instrumento de represión social contra colectivos especialmente señalados como el homosexual. Tras la muerte de Franco, el indulto de 1975 y las amnistías parciales y totales de 1976 y 1977 respectivamente no incluyen a nadie incurso en penas por transgresión de esta ley. Entrada la democracia, la ley continúa en vigor. En 1979 se eliminan algunos artículos, como los que persiguen la homosexualidad. Pero no será hasta el 23 de Noviembre de 1995 (veinte años más tarde) cuando, tras sucesivas modificaciones y suavizaciones de su contenido, se derogue por completo esta ley contra cuyo papel de estigmatizador social impropio de una sociedad moderna carga también Vázquez Montalbán:

Entre las historias de tatuajes que recordaba destacaba la de aquel pobre chorizo que se había grabado en el pecho: "Muera la policía". Había pagado cara su declaración de principios a lo largo de casi treinta años de reclusión alternante cumpliendo pequeñas condenas y arrestos por la Ley de Vagos y Maleantes. El examen del tatuaje del Madriles se había convertido 
Crónica de un desencanto: la transición a examen en la literatura ... 71

años más tarde en uno de los pasatiempos predilectos de las comisarías de todo el país.

-A ver, Madriles, déjanos ver eso, hombre.

-Le juro señor inspector que fue un mal momento. Estaba borracho y me dio por ahí. Ya me lo desaconsejó el maestro que me lo hizo; Madriles: te dará muchos disgustos.

-Uno más no importa. Anda, Madriles, quítate la camisa (Vázquez, 2001a: 27).

\section{Policíaco y Transición: impacto social}

En lo que a su fotografía a nivel social se refiere, la novela policíaca española de los años setenta reproduce a lo largo de sus páginas la nueva cartografía social emergente, en la que colectivos, cuya adscripción esta intrínsecamente arraigada en los bajos fondos suburbanos, afloran tomando la ciudad en sus calles y plazas más emblemáticas. Así, en Un beso de amigo se puede leer:

Me dejó en la calle Mayor, esquina a Postas. Le pagué sin propina y caminé hasta los soportales de la plaza. Había gente como para hacer la guerra: borrachos profesionales, pandillas de muchachos, maricones, putas abotargadas y vecinos que aprovechaban las últimas noches del verano. El Chirla estaba tirado al pie de una columna, rodeado de cristales rotos y de su propia vomitera rojiza (Madrid, 1987: 53).

Nótese también cómo estos autores alertan sobre la pervivencia de un inequívoco culto al franquismo en bastantes sectores de la sociedad. Insuflado por el repentino ascenso de la criminalidad a pie de calle durante los primeros años de la transición y fundamentado en la convicción de que la "mano dura" y las restricciones sociales durante la dictadura actuaban más eficientemente como garantes de la seguridad ciudadana $^{3}$, su presencia latente se deja ver en pasajes como este:

En la Plaza Mayor me tropecé con el Loco Vergara. [...] Estaba parado frente a la estatua de Felipe III con el brazo en alto cantando el Cara al Sol. [...] $-$

${ }^{3}$ En un momento de la narración en el que el protagonista de la saga policíaca de Juan Madrid, "Tony Romano" se acerca a pedirle trabajo a una empresa de detectives privados para la que suele trabajar esporádicamente, esta sensación generalizada la sentencia magistralmente el autor malagueño, por boca del gerente de la empresa, al comienzo de Regalo de la casa por medio de las siguientes palabras: "¿Quieres que te diga una cosa, Tony? Se está confundiendo libertad con libertinaje” (Madrid, 1996: 23-24). 
Me susurró al oído-: Esto está lleno de putas, yonkis y comunistas. [...] Ahora se pasean por todos lados. Pronto va a haber otra cruzada. [...] Ya no hay cojones, mi comandante. Antes no se dejaba con vida a los comunistas... y ahora... [...] antes era otra cosa (Madrid, 1989: 40-41).

El vertiginoso desarrollo urbano, ligado a la incipiente maduración industrial que experimenta España, provocan también un fenómeno sociológico de gran importancia y que condicionará el crecimiento urbano de las más importantes ciudades españolas durante la transición: el éxodo rural. Unido a una cada vez mayor inversión en educación superior (universitaria y de formación profesional) ante la necesidad de tecnologizar y profesionalizar el tejido económico del país, en Regalo de la casa (1986), la tercera entrega de la saga Tony Romano, Juan Madrid recrea este fenómeno, desde la crudeza y la sequedad de su estilo incisivo, a través de la imagen de un crisol heterogéneo y marcado por la desigualdad en el que coextisten profesionales en una España que va poco a poco modernizándose en materia económica con protagonistas del mundo del hampa como traficantes, chaperos, drogadictos, proxenetas y prostitutas.

Pero desde entonces ha pasado mucho tiempo. El barrio de Maravillas se ha ido llenando de modernos, camellos y de jóvenes profesionales que no quieren vivir en Parla ni en Fuenlabrada [...] Paco no me reconoció. Yo debía de ser uno de tantos que van por allí a comprar coca o heroína. O quizás un bujarrón viejo a la busca de chiquitos flacos con ganas de ganarse su papelina de caballo (Madrid, 1996: 105).

\section{Policíaco y Transición: situación económica}

Se aprecia una carga contundente en materia económica contra la perpetuación de un modelo donde la especulación inmobiliaria sigue teniendo un papel protagonista. En un contexto de necesidad de expansión urbanística, por el crecimiento demográfico causado por la demanda de mano de obra industrial y la consiguiente llegada masiva de emigrados rurales a la que aludíamos antes, se crea un caldo de cultivo propicio para la especulación. En ésta, políticos y constructores en connivencia se enriquecen ilícitamente continuando con una dinámica impulsada en la década de los 60 durante la denominada etapa del desarrollismo y que sigue los siguientes pasos:

- Común interés económico de político y empresario constructor.

- Político declara edificable un terreno. 
- Se expropia o valora a la baja el metro cuadrado de dicho terreno forzando a los pequeños propietarios a vender por debajo del coste real, cuando no a abandonar, sus parcelas.

- Empresarios constructores adquieren fácilmente el terreno y construyen "barrios dormitorios" a bajo coste, con deficientes materiales y carencias habitacionales, pero a un precio elevado aprovechando la alta demanda de vivienda.

- Político y empresario constructor se reparten su porcentaje de beneficios.

En Los mares del sur, Vázquez Montalbán aborda en profundidad este tema que, por desgracia, parece haberse convertido en una enfermedad endémica de la economía española. En esta, a la par que avanza la investigación en la que Carvalho tiene que arrojar luz sobre la muerte precisamente de un constructor, el señor Stuart Pedrell, el autor dispara las siguientes palabras:

Como Stuart Pedrell no contestaba, Carvalho concentró su interés en la barriada de Sán Magín. [...] A Stuart Pedrell se atribuían un buen puñado de especulaciones, pero sobre todo la de San Magín. A fines de los años cincuenta, y dentro de la política de expansión especulativa del alcalde Porcioles, la sociedad Construcciones Iberisa, compra bajo precio descampados, solares [...] y huertos familiares del llamado camp de Sant Magí, zona dependiente del municipio de Hospitalet. [...] En un segundo plan de construcciones, esa tierra de nadie también fue urbanizada y multiplicó por mil la inversión inicial de la constructora. San Magín fue mayoritariamente poblado por proletariado inmigrante. El alcantarillado no quedó totalmente instalado hasta cinco años después del funcionamiento del barrio. Falta total de servicios asistenciales. Reivindicación de un ambulatorio del seguro de enfermedad. De diez a doce mil habitantes. Menuda pieza estabas hecho, Stuart Pedrell (Vázquez, 2001b: 96-97).

\section{Policíaco y Transición: medios de comunicación}

Por último, en lo que al llamado cuarto poder fáctico se refiere, si bien la Transición trajo consigo en el 78 el derecho fundamental de la libertad de expresión y de la libertad de prensa, tanto Madrid como Montalbán denuncian dos aspectos fundamentales con respecto a este tema: por un lado, el control mediático y la falta de libertad a la hora de abordar ciertos temas, ahora no con la finalidad de preservar o fomentar una identidad nacional, sino en aras de mantener un el orden constitucional, 
estabilizando España desde su política interior y evitando dar voz a conflictos que pudieran generar controversia o amenazar la convivencia social. Por ejemplo, otra vez en Un beso de amigo, Juan Madrid se refiere a este problema aludiendo a la célebre publicación Cambio 16. Esta fue una revista de información general española que actuó como un medio importante en la transición política española desde la dictadura a la democracia. Nacida con formato de revista semanal el 22 de septiembre de 1971, abarcaba todo tipo de información pero predominaba en sus contenidos toda aquella relacionada con la efervescencia política de aquella época. Además, el hecho de que Juan Madrid la cite directamente no es ingenuo, ya que trabajó para la misma durante varios años como redactor.

Puso sobre la mesita una enorme cartera de cuero negro. La abrió y sacó un ejemplar de Cambio 16. En las páginas centrales había un artículo informando sobre el asalto al pub La Luciérnaga. La nota decía que se trataba de un enfrentamiento entre estudiantes de distintas ideologías. [...] - Eso es lo que hay. Ninguno de los camareros quiso decir nada, y como está cerrado no pude encontrar testigos. [...] El director no quiere que ponga el nombre del partido fascista, Resurrección Española, que está detrás de todo ello (Madrid, 1987: 67-68).

En segundo lugar, se llama la atención reiteradamente sobre la pervivencia de medios de comunicación de tradición ideológica fascista como en el caso del diario El Alcázar: periódico español de ideología franquista y ultraderechista fundado en 1936. En 1975, el periódico fue adquirido por la Confederación Nacional de Hermandades de Excombatientes y, tras la muerte de Francisco Franco, se convirtió en el medio de expresión del llamado Búnker, el grupo de dirigentes, militares y ex-militares franquistas opuestos a la transición a la democracia. Entre 1977 y $1981 \mathrm{El}$ Alcázar publicó artículos entre los que no faltaban las arengas en favor de un golpe de Estado. El periódico no cerró hasta 1988 como resultado de su falta de medios financieros para subsistir, provocada principalmente por el declive del número de lectores y por la discriminación en materia de publicidad institucional que sufrió.

Garrido estaba leyendo el diario El Alcázar con los pies sobre la mesa de un pequeño despacho acristalado que parecía una portería. En uno de los rincones había un perchero, probablemente sobrante de la sala de espera de un no- 
Crónica de un desencanto: la transición a examen en la literatura... 75

tario de provincias, una radio antigua y un mueble fichero de fuelle (Madrid, 1989: 157)

La crítica se hace doblemente mordaz al incorporar Madrid estas lecturas a pie de calle en contextos de lo más cotidianos. Presencia llamativa tratándose de un activo ideologizante tan subversivo para la bisoña democracia española.

El gimnasio era una nave en el paseo de la Flirda rodeada de un jardín polvoriento y sin cuidar. [...] No había nadie en la puerta. [...] En el fondo una escalera conducía al piso superior y un cartel señalaba las saunas. [...] Al lado, un tipo gordo y calvo, retrepado en una silla frente a una mesa pequeña, leía El Alcázar, sosteniéndolo con sus manos deformes (Madrid 69).

\section{Conclusión}

A modo conclusión, en un país en el que no se había registrado un cultivo digno de mención en lo que respecta a la narrativa policíaca, la transición democrática trae consigo los condicionamientos políticos, editoriales y socio-históricos necesarios para que esta narrativa eclosione con fuerza en un país que abandona el ruralismo predominante y que empieza a experimentar las importantes transformaciones que trae consigo el desarrollo industrial, su paralelo crecimiento urbano y sus consecuentes problemáticas sociales. Enraizada en este contexto, la literatura criminal española de esta época -entre cuyos autores destacan sobre manera las propuestas madrileña y barcelonesa de Juan Madrid y Vázquez Montalbán respectivamente- se erige como un elemento de reflexión crítica sobre, precisamente, los hitos de esa Transición que la dio a luz en torno a cuatro ejes principales.

Desde el punto de vista político, la obra de estos autores pone el foco sobre la ausencia de una ruptura total con respecto a las estructuras de poder franquista, denunciando la pervivencia de varias de sus políticas y encrucijadas ideológicas.

A nivel social y a nivel económico, no solo se hacen eco de las grandes transformaciones experimentadas por la ciudadanía española, retratando la nueva cartografía urbana surgida del masivo éxodo rural a ciudades como Madrid o Barcelona tras la consolidación de las bases de producción capitalista, sino que se incide en las onerosas consecuencias 
en términos de corrupción, desigualdad y violencia que de estas se desprenden.

Para terminar, la denuncia del control institucional del estamento mediático y la subsistencia de medios de comunicación de corte extremista hasta bien entrada la transición se constituirá como el cuarto eje de reflexión dentro de la producción narrativa policíaca de estos dos autores.

Todo ello con el objetivo último de denunciar la pervivencia nociva de muchos aspectos con los que, en materia política, social, económica o mediática, no se había roto tan de raíz como, según ambos autores, hubiera sido necesario.

\section{Bibliografía}

Bados, María C. "Feminización de la novela policiaca: alternativas para el cambio sociocultural" La imagen de la mujer y su proyección en la literatura, la sociedad y la historia 91.4 (2010): 27-48.

Balibrea, María P. "La novela negra en la transición española como fenómeno cultural: una interpretación" Iberoamericana 7. 2 (2002)111-118.

Close, Glen. "The Novela Negra in a Transatlantic Literary Economy" Iberoamericana 21.1 (2006): 115-131.

Colmeiro, José. La novela policíaca española: teoría e historia crítica. Barcelona: Anthropos, 1994.

Fernández, José. "Mitos imperfectos: Observaciones de un lector continental en torno a la novela policiaca" Revista de Occidente 55, 19 (1967):1-13.

García, Francisco. Las hermanas coloradas. Barcelona: Bibliotex, 2001.

González, Francisco. "La prehistoria de la novela negra" Los cuadernos del norte 41 (1987) 10-14.

Luzán, Julia. "Interrogatorio" Gimlet: revista policíaca y de misterio 4. 2 (1981) 31-42.

Madrid, Juan. Un beso de amigo. Gijón: Júcar, 1987.

---. Las apariencias no engañan. Gijón: Júcar, 1989.

---. Regalo de la casa. Madrid: Alfaguara, 1996.

Vallés, José R. La novela criminal española. Granada: Ediciones Universidad de Granada, 1991.

Vázquez de Parga, Salvador. La novela policiaca en España. Barcelona: Ronsel, 1993. 
Crónica de un desencanto: la transición a examen en la literatura ... 77

Vázquez, Manuel. Los pájaros de Bangkok. Barcelona: Planeta, 1990.

---. Tatuaje. Barcelona: Bibliotex, 2001a.

---. Los mares del sur. Barcelona: Bibliotex, 2001b. 